\title{
Wake-Up. A Health Promotion Project for Sub-Saharan University Students: Results of Focus Group Sessions
}

\author{
Jesca Mercy Batidzirai ${ }^{1}$ \\ G Anita Heeren² \\ C Show Marange ${ }^{3}$ \\ Arnold Rumosa Gwaze ${ }^{3}$ \\ Andrew Mandeya ${ }^{3}$ \\ Zolani Ngwane ${ }^{4}$ \\ John B Jemmott III2 \\ Joanne C Tyler ${ }^{3}$ \\ ${ }^{1}$ School of Mathematics, Statistics and Computer Science, University of KwaZulu-Natal, \\ Private Bag X01, Scottsville, 3209, Pietermaritzburg, South Africa, \\ 2Department of Psychiatry, Department of Communication and Health Behavior, Perelman School of Medicine, \\ University of Pennsylvania, Market Street 3535, Suite 520, Philadelphia PA 19104, USA \\ ${ }^{3}$ Department of Biostatistics, University of Fort Hare, Private Bag X1314, Alice, South Africa \\ ${ }^{4}$ Department of Anthropology, Haverford College, Lancaster Road, Haverford PA 19030, USA \\ Corresponding author address: e-mail: jesbats@gmail.com
}

\section{Doi:10.5901/mjss.2014.v5n7p346}

\section{Abstract}

HIVIAIDS is seen as the major killer in developing countries however, non-communicable diseases (NCDs), also referred to as chronic diseases, are the leading causes of death worldwide. University students are an important target for health promotion programmes because they are exposed to a new lifestyle where they have to determine on their own which diet to follow, whether or not to exercise, how much they drink alcohol or smoke, whether to have sex or abstain, as well as whether to practice safe sex or not. Focus group sessions were held at a rural Sub-Saharan African University to assess students' knowledge on how to lead a healthy lifestyle. The results suggest a need for a health promotion intervention programme which should be culture-sensitive and considerate of the needs of university students.

Keywords: Focus group, Health promotion, Sub-Saharan Africa, University Students

\section{Introduction}

Non-communicable diseases (NCD) are one of the leading causes of death worldwide. In 2008, nearly $80 \%$ of noncommunicable disease deaths 29 million occurred in low- and middle-income countries with about $29 \%$ of deaths occurring before the age of 60 in these countries. The leading causes of NCD deaths in 2008 were cardiovascular diseases (17 million deaths, or 48\% of all NCD deaths), cancers (7.6 million, or 21\% of all NCD deaths), and respiratory diseases, including asthma and chronic obstructive pulmonary disease (4.2 million or 7.0\%). Diabetes caused another 1.3 million or 4.4\% deaths (WHO 2014). By the year 2030, low-income countries will have eight times more deaths attributed to NCD than high-income countries (UNAIDS, 2010).

In South Africa a large portion of the morbidity and mortality each year can be attributed to NCD (Joubert J et al., 2007; Norman CD., et al., 2007; Schneider M et al, 2007). There is a growing recognition of the potential impact of these NCD on morbidity and mortality among South Africans (Alberts M. et al 2005; Asfaw, A. 2006; Steyn K et al 2006). More than one-third (37.5\%) of young adults aged 18 to 24 years engaged in insufficient physical activity. A significantly higher percentage of black (37.5\%) and coloured students (45.6\%) than white students $(29.4 \%)$ engaged in insufficient physical activity Amosun SL, Reddy PS, Kambaran N, Omardien R. 2007). 
Besides NCD, HIVIAIDS is another cause of death. More than one third of the people living with HIV globally and over half of the newly infected persons in the year 2010 were under the age of 25 (UNAIDS, 2010). In South Africa, the overall HIV prevalence rate is approximately $10.6 \%$ and the total number of people living with HIV is estimated at approximately 5.38 million in the year 2011 (STATSSA, 2011). Furthermore, 16.6\% of the adult population aged 15 to 49 years is estimated to be HIV positive. Approximately one-fifth of South African women in their reproductive ages are HIV positive (STATSSA, 2011). HIVIAIDS is having a devastating impact on the country, especially on young people of university age.

University students, like their peers in the same age group, are at a high risk of contracting HIVIAIDS. Increased income or educational attainment does not reduce or eliminate the risk of HIV infection among South Africans. Shisana \& Simbayi (2002), showed in their study that there was no significant relationship between income and HIV prevalence among black South Africans. In addition, among black South Africans of 25 years of age and older, there is actually a significant increase in HIV prevalence with increasing levels of education. Deshpande et al (2009) point out that the transition to personal independence living during the years spent at university is an imperative factor. NCD are preventable diseases and influenced by life style. Universities have the unique opportunity to influence and mould young adults before they enter the real life. These institutions might be able to influence the lifestyle of young people for the future not only academically but also in the direction of a healthy life style (Wegner, Fisher, Caldwell, Vergnani, \& Smith, 2008); (El Ansari, Stock, \& Mikolajczyk, 2012).

\subsection{Literature Review}

The challenge to provide 'evidence' based health promotion programmes (Ewles, L.; 1999) has been initiated by some researchers through the development of interventions based on the social cognitive theory, and the theory of planned behaviour (TPB), utilising quantitative and qualitative data, which is likely to influence behaviour change (Fishbein 1975; 1991; Jemmott JB, 2012). Some of these interventions have been implemented and evaluated in clinical trials, mainly in developed countries (Jemmott JB 2010; Werch CE et al 2007), but only few interventions have been designed and applied in developing countries (Jemmott JB et al 2011; 2012; Heeren GA et al 2013).

According to literature, no theoretical model has been rigorously tested or even advanced to explain sexual risk behavior in South Africa (Jemmott, et al., 2010; Heeren GA. eta I 2013). The theory of reasoned action/planned behavior can make an excellent choice for applied research in South Africa and it is flexible in that it allows diversity to be taken into account. An example of this flexibility is that the theory explicitly states that the predictors of behavior vary depending on the particular behavior and population. Further, it states that the predictors can be identified through elicitation research conducted on the population. This serves to tailor the theoretical model to the population (Jemmott J. B., 2012).

Information from formative research, such as qualitative studies in focus groups and quantitative studies like surveys might be used in conjunction with the TPB to develop an intervention that is not only theoretically grounded, but also developmentally and contextually appropriate for university students as the target population. The main advantage of focus group sessions, according to Krueger (2006), are a valid and reliable method for collecting data, and are much more flexible than surveys or scales. He argues that it is mainly because focus group sessions allow for question clarification and follow-up questions to probe vague or unexpected responses. Among the characteristics of efficacious health interventions is the presence of a theoretical framework that has been effective in changing other health-related behaviors (Kirby, Laris, \& Rolleri, 2007).

The $20^{\text {th }}$ century has seen a number of studies in health research that used focus group sessions as a tool for exploring knowledge and opinions on health related topics among the study participants. According to literature, focus group sessions have been commonly used in the U.S, Europe and Asia, whilst a limited number of the studies targeted university students (Wong, 2008); (Deshpande, Basil, \& Basil, 2009); (Wechsler, Devereaux, Davis, \& Collins, 2000); Heary \& Hennessy, 2002). In Sub-Saharan Africa, limited research has been recorded on focus group sessions with university students. These are studies conducted in Zimbabwe (Terry, Masvaure, \& Gavin, 2005) and (Terry, Mhloyi, Masvaure, \& Adlis, 2006), Botswana (Mogobe, Seboni, Brown, Ntsayagae, Sebego, \& Sabone, 2007) and South Africa (Jemmott, et al., 2010; Heeren GA et al 2013).

The hypothesis of this study, using focus group sessions, was to determine if university students would be willing to attend a health promotion programme and test their knowledge in regard to health risk behaviour such as STI/HIV and NCD.

This paper presents the results of focus group sessions at a rural-based South African university. In these focus group sessions, it was important to gain access to knowledge and understanding about practices, attitudes and behaviour that university students present concerning sexual behavior, STI/HIV, condom use, multiple sexual relationships, healthy 
life style including healthy diet, fruit, vegetable, alcohol consumption, and physical exercise.

\section{Methodology}

\subsection{The study design}

In preparation for the development of the health promotion and health risk reduction interventions for a health promotion programme for university students, the theory of planned behavior (Ajzen I, 1985; Ajzen I, 1991) has been applied combining formative research methods using qualitative research administering focus group sessions and surveys (Heeren GA et al 2013). Focus group sessions are often used in preparation for pilot studies for use in developing intervention curricula (Mansell I et al 2004; Jemmott III J et al 2010; Heeren GA et al 2012).

\subsection{Recruitment}

Participants were recruited from across campus through flyers posted in public spaces and announcements in lecture halls. Screening criteria were that the student had to be registered at the university and in the age group between 18 and 28 years. The students who met these criteria were invited to a specific office to register and positively identify themselves as bona fide registered student at the university. The focus group sessions were categorized by gender, (males and females), nationality (South Africans and non-South Africans) and mixed gender and mixed nationality. Due to cultural beliefs that males and females might not talk openly in the presence of the opposite gender, single gender sessions were held. Further concern was that out of politeness, non-South Africans might not comment on their views of some of the issues that were discussed in the presence of South Africans and vice versa, the sessions for nationalities were also held separately. These characteristics were expected to have a bearing on the outcome of the study.

\subsection{Sessions}

At the start of each session, participants and facilitators developed some group rules. Confidentiality was the most common rule among all groups. With prior permission from participants, the sessions were audiotaped, which included verbatim conversations. Additionally, research assistants took notes during the sessions.

\subsection{Data Collection}

Prior to each session, the participants completed a pen and paper questionnaire. This questionnaire collected information about their socio-economic and demographic background, health risk behavior and other health related issues. The students developed the logo for the study as well as the motto of the study, which became: "Wake-up".

\subsection{Data analysis}

A thematic approach was used to analyze the data. The researchers developed categories of themes and sub themes. These were then given codes that were related to the data they represented and analysed by the researchers. The data was then 'cleaned' and reduced to small manageable portions according to the identified themes. Data analysis was conducted by groups divided into single gender, nationality as well as mixed gender and mixed nationality. Data were compared regarding male and female beliefs, attitudes and behaviour, especially their practice concerning health risk behavior such as STI/HIV, sex, condom use, abstinence, multiple sexual relationships, healthy diet, fruit and vegetable as well as alcohol consumption and physical activity.

\subsection{Ethics committee}

The Institutional Review Board of the University of Pennsylvania and the Ethical Committee of the collaborating University of Fort Hare approved the study. Students signed a consent form and a registration form prior to the sessions. 
Refreshments were served during the focus group sessions. Students received R30 (equivalent of $\$ 6.00$ ) as a token of appreciation for their time.

\section{Results}

\subsection{Participants}

Nine focus group sessions with 108 students, with 12 students per session, were conducted at a South African rural based multicultural university. The students came from different parts of South Africa and from other African countries like Zimbabwe, Lesotho, Botswana, Swaziland, Nigeria, Kenya and Congo. Half of the participants were males and half were South Africans, they were in the age group between 18 to 28 years, with a mean age of 22.8 years. Figure 1 below shows the distribution of the sessions.

Figure 1: Bar graph of the distribution of students by gender and nationality

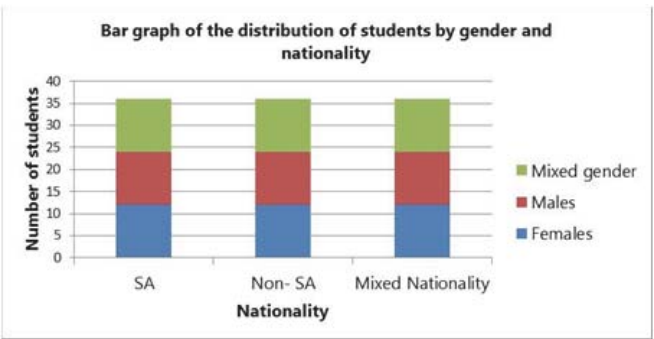

The focus group sessions followed an especially designed protocol. Each session had the same questions and questions were asked in the same order. The questions focused on their general interest and willingness to participate in a health promotion programme. The topics in the sessions included STI/HIV and AIDS, condom use, multiple sexual partnerships and relationships, sex and abstinence, general health issues, diet, exercise, drugs and alcohol, whilst living on campus. Students were also asked about the kind of facilitators they thought they would feel most comfortable with for the group sessions if a health promotion intervention were to be conducted. They suggested having graduate students from their university rather than outside facilitators. The students suggested that an intervention programme should be held at the beginning of the year because students do not yet have examinations and tests to write and would have more time to focus on something they might want to learn without receiving any academic credits for. Furthermore, students would be more flexible and able to determine the time for participation in the intervention.

The choice of the title of the health promotion intervention programme was very challenging with many suggestions. The researchers together with the students agreed for the title "Wake-up" which colloquially mean "Be vigilant and also watch out for your health' but also 'Take over responsibility' for yourself. During these sessions they came to an understanding of the importance of leading a healthy life style and the negative influence for their future of not eating healthy, not being physically active, drinking too much alcohol, having unprotected sex, having many sexual partners. This was like a "Wake-up" call for many and they decided to start to accept that each person is responsible for their own health. Therefore it was time to "Wake-up" and change one's owns behavior.

\subsection{STI/HIV and AIDS}

The focus group sessions showed that the participants of all groups were aware of STI's such as syphilis, gonorrhea, herpes, chlamydia, HPV and HIVIAIDS, as well as their ways of transmission, especially through unprotected sex. They believed that STI has symptoms always. They knew that they should get tested frequently, but they expressed fear of stigmatization, and ignorance. Students said, "We would rather not know our status because of the stress of knowing". Non- South African males mentioned some risky behaviors that may lead to HIV transmission, such as watching pornography, multiple sexual partners, drugs and too much partying. Non- South African females suggested ways of 
preventing STI's such as abstinence, being faithful to one partner, use of condoms, non-penetrative sex, self-respect and discipline.

\subsection{Condom use and multiple sexual partners}

According to the discussions in the focus group sessions, South African students seem to have more sexual partners than non-South African students. These comments were especially made in the mixed nationality and mixed gender sessions. In the male only sessions, students reported that: "Females are the ones who cheat more than males" and the female gender group believed that "males cheat on us more".

In the same gender sessions, female participants agreed that most men who do not drink are the ones who have multiple sexual partners because, "the sober man has got nothing to do". They said: "males get into a relationship for sex", to "have someone who does their laundry and cooking", and "to have someone to produce babies for them" and that male students referred to the female students as "the baby factory."

Whilst they preferred not to say this in mixed gender sessions, non-South African male students indicated in same gender sessions that they have multiple partners to feel variety and gain experience. They said, "Ladies are like weather because they can change anytime. So, you need to have a backup girlfriend whom you can have sex with when your girlfriend does not want to". They seem to think multiple partners are good and their only concern is "not to be caught by their steady girlfriends".

In the female only session they said: "we do not always have the power over men to discuss condom use in the relationship" and "men come up with all sorts of excuses" like, "it's too tight", "it doesn't feel good", and "I don't feel anything", and "it gives me a rash", in order to try and convince the female sex partner to have unprotected sex. In the male only sessions students said, "if the lady does not initiate the topic of condom use, then we also do not care" and "alcohol and drugs have an influence on condom use". Across all the nine sessions, all the participants said it was easy to limit the number of sexual partners if "your partner is also faithful," "if you get sexual satisfaction in your relationship", "if you have good friends" and "if you are financially stable".

In the single gender groups and mixed gender as well as nationality group sessions, some of the participants indicated that they knew the consequences of multiple sexual partnerships and not using condoms, which included unwanted pregnancies, STI and HIV transmission. Male participants said it is always good to carry condoms in their pockets and keep some under their pillows. The main barrier to use condoms was that condoms are expensive and they did not trust the free condoms. Free condoms are available at the university campus, at the clinic and are accessible in bathrooms.

Mixed gender groups also suggested that long-term relationships are a barrier to condom use as they tend to develop trust between partners, so "they end up not using condoms". Another barrier to condom use mentioned in the male only gender sessions was "alcohol abuse which would lead to irresponsible sexual behavior". Some students gave "religious" reasons for not using condoms.

In the South African female only sessions the students said they bought condoms more than the male students, "who either always choose to use free and poor quality condoms or no condom at all". They also believe that ladies are at more risk of HIVIAIDS than men.

\subsection{Relationships, sex and abstinence}

In general, there seems to be an impression by all students that they have sexual relationships "for fun, to kill time, to gain status, because they have the freedom, due to peer pressure, because it's the normal thing to do and also because they expect the relationships to lead to marriages". The group for non-South African female students talked more of "abstinence, long term relationships and relationships that lead to marriages" than any other group. They pointed out that a person should "avoid too much kissing, touching and drinking with her boyfriend as these can lead to unexpected sex".

Some of the female students mentioned that it is "hard to abstain because of poverty". They said that they "need money to afford the normal university lifestyle" and would "at times trade their bodies to men" who are "willing to provide for their needs". The South African female group said they have "different sexual partners, one for buying airtime, and another for clothes, another one for food, and another for money", (they call them "Mr. Airtime, Mr. Clothes" etc., respectively). The male participants said it is "now difficult to abstain because the media is always talking about sex", and "they watch too much of pornography". South African male participants talked more of "one night stands" than "a relationship". They also talked of having one steady sex partner (not a girlfriend) that "you can only call when you need sex with no 'strings attached"'. They said "we could easily get bored with a girl after having sex with her" and "leave her", 
which "makes it difficult to have a steady relationship".

\subsection{Diet}

Students gave the impression they knew the influence of an unhealthy diet and its possible influence on health. They complained that a healthy diet would be too expensive to follow. Unlike female students, male students admitted that they "eat a lot of bread" because, they said, "we do not have time to cook", "we are lazy to cook" and also that "we do not know how to cook". Most students did eat fruits and vegetables but not on a regular basis as they argued, "fruits are expensive and not easily available". Although many female participants ate cereal for breakfast, they mentioned that, "at times, we take time to prepare a good meal". The female participants included various vegetables in preparing their meals. The male students found vegetables to "be not so good tasting". Rice and pap (a meal made from maize or corn) are staple foods for most students in the groups from Southern African countries.

\subsection{Exercise}

Across all the groups, both male and female students did not exercise regularly, even though they were aware that exercise is good for their health. Males, both South Africans and non-South Africans, stressed that they would rather "have sex", because "we enjoy to sexercise rather than exercise", (a word they use for having sex as a form of exercise) and "so that we sweat rather than going to the gym, which is boring". Both male and female participants confirmed that, "we do not have time for exercises", and some said: "we are just lazy to do so". They gave excuses that mornings are the only times they could exercise, but it is usually very cold then. (Note: at the time the sessions took place, it was in winter).

One of the barriers for the students for not being physically active was, "We do not have a gym on campus", and the only proper gym they knew was expensive and located in town, approximately a $2 \mathrm{~km}$ walking distance outside campus. The female participants were more discouraged by the long distance they have to walk to reach the gym. The gym at the campus is poorly maintained. In the mixed nationality female session, female students thought that male students are more committed to exercising than female students. Ladies justified themselves that, "we walk long distances around campus" and "as we walk to classes", defending "we do not need to do more exercises". (Note: There is no transport between the accommodation and the classrooms). There are sports facilities available on campus but the students said: "very few students go there, because of time and friends also discourage them to go". There seems to be no difference in physical activities among nationalities.

\subsection{Alcohol use}

The results from the focus group discussions seem to indicate that generally, students drink a lot. In mixed gender and mixed nationality group sessions, students did not agree on limiting themselves to "three beers a day" as they said "it is too little". In both mixed gender sessions and same gender sessions, male students from all nationalities said "they drink to get drunk", and to "take away stress", especially when there are parties, as well as during weekends. In the female only sessions, South African ladies said: "males drink more than females". All participants said "they drink because they have nothing entertaining on campus", "to utilize their freedom" and also because "they have no money to do better things".

Generally, the results of the sessions seemed to show that male and female students smoke cigarettes. Males said they "use drugs when having sex". They said, "Holy gold gives you an erection and you can have more rounds", (meaning the effect of drugs that gives them energy to perform sexually well). They said: "they can drink again if they have a hangover", unlike females who do not drink when they have a hangover. Non-South African female students did not indicate that they were smoking or drinking, but they said males "beat up" their girlfriends when they get drunk, "they start singing some songs and shouting" and "most people take that opportunity to express what they have been keeping for a long time, because they won't be shy anymore". In female only sessions the students gave the impression that male students would use alcohol as an excuse for abusive behavior. The students all agreed that limiting drinking saves money and keeps a person healthy.

\section{Discussion}

As predicted, the group with mixed gender and mixed nationalities were not openly discussing certain topics as the single gender or national groups. Female students seem to know more about healthy life style than males, while males seem to exercise more than females. Male students seem to choose not to eat healthy food because they do not know how to 
cook. Also, sexual risk behavior was found more commonly in the group of the South African students (i.e. choosing to have more sexual partners and alcohol consumption) than in the non-South African students. Compared by gender it also showed that risky sexual behavior was found to be more pronounced among male students than among the females.

Abstinence belief was mainly discussed by non-South African female students; however all females students expressed that their male partners are only after sex. Male students would not agree on condom use, whereas some female students feel they have no power to tell their sexual partners to use condom. On campus free condoms are available from the clinic and can be found in bathrooms, but they are not the preferred brands. Students would rather buy their preferred brands, which happen to be expensive for them. This may actually compromise condom use habits among students. This study confirms that multiple sexual partners do not depend on gender. Within a steady relationship, condoms are not used because partners develop trust as the relationship grows, ignoring the danger of serial monogamy relationships. Generally, students agree that there are greater chances of condom misuse or no use at all, when students engage in sexual intercourse while in a drunken state.

Male students are significantly more likely to engage in drug-taking behaviors (Stock, Wille, \& Krämer, 2001). This was verified in these focus group discussions. There was a gender difference in drug and alcohol consumption. Female students tend to take drinks that have less alcohol content than male students.

Fregapane et al. (2000) concluded in their study that an effective nutritional education programme that stresses the importance of increased consumption of food rich in starch and reducing those containing more protein, cholesterol, fat and sugar levels so as to improve dietary habits would be important. The results of the focus group sessions also showed that university students chose a diet which was not necessarily balanced or healthy which might lead to an increase of NCD in the future. This is especially true with male students who reported eating mostly bread and more often alcohol use. The connection between healthy lifestyle and health condition seemed not to be well known. Healthy diet, alcohol and physical activity had been seen as either expensive or boring.

Universities in general have a responsibility to not only train the students in their academic development but also guide them to develop healthy lifestyle skills for the future. Students are the countries' future leaders and present the role models. The students need guidance for all of these roles.

In conclusion, focus group discussions have proved to be a useful instrument for student participation in health promotion programmes, understanding student's opinions as well as assessment of students' knowledge in regard to health risk reduction and health promotion. The results of the focus group sessions showed that there is a need for a health promotion intervention at university level. This might increase young people's knowledge on healthy lifestyle and might change their behavior and attitude towards life style decisions and understanding their own responsibility.

\section{Conclusion}

\subsection{Recommendations}

Universities are in a unique position training and preparing young people for life beyond the academic development. The universities might want to consider to offer not only academic training, but also lifestyle skills and affordable healthy meals for the students.

Students are role models to others and it is important that they understand their own responsibility for not only excelling academically but also in leading a healthy lifestyle. In regard to condom availability, it might also be recommended that the providers of free condoms may try to manufacture condoms with variety so that everyone may have access to good quality condoms.

\subsection{Limitations}

Limitations of this study were that, in as much as focus group discussions are a good way to collect information from students, some bias might arise due to the selection of participants. The results shown during the sessions are the opinions presented by the students present at the sessions and might not necessary represent the whole population at the university.

\subsection{Acknowledgements}


The study was made possible in part by an NIH grant R34MH078803. We wish to thank all students and facilitators for participating in the sessions and for their valuable contribution. We wish to thank Prof Justin Sitron, Prof Jillian Baker and Mr. Raymond Chiruka for their assistance during the focus group sessions.

\section{References}

Ajzen, I. (1985). From intentions to actions: A theory of planned behavior. In J. Kuhl, \& J. Beckmann, Action Control: From cognition to behavior (pp. 11-39). Springer.

Ajzen, I. (1991). The theory of planned behavior. Organizational Behavior and Human Decision Processes, 179-211.

Alberts M. Urdal P, Steyn K, Stensvold I, Tverdal A, Nel JH, Steyn NP. (2005). Prevalence of cardiovascular diseases and associated risk factors in a rural black population of South Africa. Eur J Cardiovasc Prev Rehabil, 12(4):347-54.PMID: 16079642 [PubMed indexed for MEDLINE]

Amosun SL, Reddy PS, Kambaran N, Omardien R. (2007). Are students in public high schools in South Africa physically active? Outcome of the 1st South African National Youth Risk Behaviour Survey. Can J Public Health, 98(4):254-8.

Asfaw, A. (2006). The effects of obesity on doctor-diagnosed chronic diseases in Africa: empirical results from Senegal and South Africa. Journal of Public Health Policy. 2006;27(3):250-64. PMID: 17042123 [PubMed - indexed for MEDLINE]

Deshpande, S., Basil, M. D., \& Basil, D. Z. (2009). Factors influencing healthy eating habits among college students: an application of the Health Belief model. Health Marketing Quarterly, 26(2), 145-164.

El Ansari, W., Stock, C., \& Mikolajczyk, R. T. (2012). Relationships between food consumption and living arrangements among university students in four European countries - A cross-sectional study. (1475, Ed.) Nutrition Journal, 11(28), doi:10.1186/1475-2891-1128.

Ewles L. (1999) Health improvement programmes. Avon calling. Health Serv J. Jun 24;109(5660):24-5.

Fishbein, M. Ajzen, I.(1975) Belief, attitude, intention and behavior: An introduction to theory and research Authors: Pagination: 578p. Publication Date: 1975. ISBN: 0201020890

Fishbein, M., \& Aizen, I. (2010). Predicting and changing behavior: the reasoned action approach. New York: Taylor and Francis Group.

Fregapane, G., \& Asensio-García, C. (2000). Dietary assessment of an educated young Spanish population using a self-administered meal-based food frequency questionnaire. European Journal of Epidemiology, 16(2), 183-191.

Heary , C. M., \& Hennessy, E. (2002). The use of Focus Group Interviews in Pediatric Health Care Research. Journal of Pediatric Psychology, 27(1), 47-57.

Heeren GA, Jemmott JB 3rd, Sidloyi L, Ngwane Z, Tyler JC. (2012). Disclosure of HIV Diagnosis to HIV-Infected Children in South Africa: Focus Groups for Intervention Development. Vulnerable Child Youth Stud, 7(1):47-54. Epub 2012 Feb 24. PMID: 22468145 [PubMed]

Heeren GA, Jemmott JB 3rd, Ngwane Z, Mandeya A, Tyler JC. (2013). A randomized controlled pilot study of an HIV risk-reduction intervention for sub-Saharan African university students. AIDS Behavior, 17(3):1105-15. doi: 10.1007/s10461-011-0129-2. PMID: 22246515 [PubMed - indexed for MEDLINE]

Heeren GA, Mandeya A, Marange CS, Batidzirai JM, Tyler JC. (2013). Health Promotion Project for University Students at a South African University: Results of a Pilot Survey. Journal of Human Behavior in the Social Environment, 23(8), 967-971

Jemmott, J. B. (2012). The Reasoned Action Approach in HIV Risk-Reduction Strategies for Adolescents. The ANNALS of the American Academy of Political and Social Science, 640(1), 150-172.

Jemmott JB 3rd, Jemmott LS, O'Leary A, Ngwane Z, Icard L, Bellamy S, Jones S, Landis JR, Heeren GA, Tyler JC, Makiwane MB. (2011). Cognitive-behavioural health-promotion intervention increases fruit and vegetable consumption and physical activity among South African adolescents: a cluster-randomised controlled trial. Psychol Health. 2011 Feb;26(2):167-85. doi: 10.1080/08870446.2011.531573. PMID: 21318928

Jemmott, J. B., Jemmott, L. S., O'Leary, A., Ngwane, Z., Icard , L. D., Bellamy, S. L., Jones S.F., Landis J.R., Heeren G.A., Tyler J.C., Makiwane M.B. (2010). School-based randomized controlled trial of an HIVISTD risk-reduction intervention for South African adolescents. Archives of Pediatrics Adolescence Medicine, 164(10), 923-9.

Jemmott JB 3rd, Jemmott LS, Fong GT, Morales KH. (2010) Effectiveness of an HIVISTD risk-reduction intervention for adolescents when implemented by community-based organizations: a cluster-randomized controlled trial. American Journal of Public Health, 100(4):720-6. doi: 10.2105/AJPH.2008.140657. Epub 2010 Feb 18. PMID: 20167903

Joubert J, Rao C, Bradshaw D, VoS T, Lopez AD. (2007). Evaluating the quality of national mortality statistics from civil registration in South Africa, 1997-2007. PLoS One. 2013 May 27;8(5):e64592. doi: 10.1371/journal.pone.0064592. Print 2013. PMID: 23724066 [PubMed - indexed for MEDLINE]

Kirby, D. B., Laris, B. A., \& Rolleri, L. A. (2007). Sex and HIV Education Programs: Their Impact on Sexual Behaviors of Young People Throughout the World. Journal of Adolescence Health, 40(3), 206-217.

Krueger, R. A. (2006). Is it a Focus Group? Tips on How to Tell. Journal of Wound, Ostomy \& Continence Nursing, 33(4), 363-366.

Mansell I, Bennet G, Northway R, Mead D. Moseley L. (2004). The learning curve: the advantages and disadvantages in the use of focus groups as a method of data collection. Nurse Res, 11 (4):79-88. [PubMed]

Mogobe, K. D., Seboni, N., Brown, M. S., Ntsayagae, E., Sebego, M., \& Sabone, M. (2007). HIVIAIDS education, prevention and control course (BNS101): the way forward. The Journal of the Association of Nurses in AIDS Care, 18(6), 22-31. 
Norman CD1, Skinner HA. (2007) Engaging youth in e-health promotion: lessons learned from a decade of TeenNet research. Adolesc Med State Art Rev, 18(2):357-69, xii.

Schneider M, Norman R, Steyn N, Bradshaw D. (2007). Estimating the burden of disease attributable to low fruit and vegetable intake in South Africa in 2000. South African Comparative Risk Assessment Collaborating Group. S Afr Med J,97(8 Pt 2):717-23. PMID: 17952229 .

Shisana, O., \& Simbayi, L. C. (2002). Nelson Mandela/HSRC study of HIVIAIDS: South African national HIV prevalence, behavioural risks and mass media: household survey. Cape Town: Cape Town Human Science Research Council.

STATSSA. (2011). Statistical release P0302. Mid-year population estimates 201. Statistics South Africa.

Steyn K, Damasceno A. (2006) Lifestyle and Related Risk Factors for Chronic Diseases. In: Jamison DT, Feachem RG, Makgoba MW, Bos ER, Baingana FK, Hofman KJ, Rogo KO, editors. Disease and Mortality in Sub-Saharan Africa. 2nd edition. Washington (DC): World Bank; 2006. Chapter 18. PMID: 21290651 [PubMed]

Stock, C., Wille, L., \& Krämer, A. (2001). Christiane Stock, Lutz Wille and Alexander Krämer. (2001).Gender-specific health behaviors of German university students predict the interest in campus health promotion. Oxford Journals.16, Issue 2. Pp. 145-154. Health Promotion International, 16(2), 145-154.

Terry, P. E., Masvaure, T. B., \& Gavin, L. (2005). HIVIAIDS health literacy in Zimbabwe--focus group findings from university students. Methods of information in medicine, 44(2), 288-92.

Terry, P. E., Mhloyi, M., Masvaure, T., \& Adlis, S. (2006). An examination of knowledge, attitudes and practices related to HIVIAIDS prevention in Zimbabwean university students: comparing intervention program participants and non-participants. International Journal of Infectious Diseases, 10(1), 38-46.

UNAIDS. (2010). Global report: UNAIDS report on the global AIDS epidemic, 2010. Retrieved from http://www.unaids.org /globalreport/global_report.htm.

Wechsler, H., Devereaux, R. S., Davis, M., \& Collins, J. (2000). Using the School Environment to Promote Physical Activity and Healthy Eating. preventive medicine, 31(2), s121-s137.

Wegner, L., Fisher, A. J., Caldwell, L. L., Vergnani, T., \& Smith, E. A. (2008). Healthwise South Africa: cultural adaptation of a schoolbased risk prevention programme. Health Education Research, 23(6), 1085-96.

Werch CE, Bian H, Moore MJ, Ames S, DiClemente CC, Weiler RM. (2007). Brief multiple behavior interventions in a college student health care clinic. J Adolesc Health, 41(6):577-85. Epub 2007 Sep 4. PMID: 18023787

WHO 2014 at: http://www.who.int/gho/ncd/mortality_morbidity/en/

Wong, L. P. (2008). Focus group discussion: a tool for health and medical research. Singapore Medical Journal, 49(3), 256-260. 